\title{
Clinical reactions to Aspergillus niger in a biotechnology plant: an eight year follow up
}

\author{
Anthony Seaton, Doreen Wales
}

\begin{abstract}
The manufacture of citric acid by fermentation of molasses with Aspergillus niger has previously been described as a cause of occupational asthma in a factory. A longitudinal survey of the workforce of this factory has been carried out from 1984 to 1991 . Over this period 160 of the original 278 workers left the workforce, together with 39 of 76 new recruits. Partial enclosure of the process and exhaust ventilation, installed in 1984, was effective in preventing any new cases of occupational asthma over the eight year period, and no new skin sensitisation was detected. Spore counts of $\boldsymbol{A}$ niger averaged about 100 times those in the outside air. Health in the 1984 survey had a striking influence on subsequent retiral; only 11 of the 79 with respiratory symptoms remained in 1991, compared with 90 of the 182 with no symptoms. In conclusion $A$ niger is a weak antigen and simple hygiene measures protect the workforce. Exclusion of recruits with positive skin tests is not necessary if such measures are taken. The survey provided evidence of the selection factors operating within a workforce over this period contributing to retiral of the less healthy.
\end{abstract}

(Occup Environ Med 1994;51:54-56)

Asthma due to exposure to the antigen from Aspergillus niger used in the production of citric acid was first described in a workforce in 1985. ${ }^{1}$ The factory in question used $A$ niger to ferment molasses, partly by an open and partly by a closed method. ${ }^{1}$ In that investigation, eight of the workforce of 343 were diagnosed as having occupational asthma with sensitisation to $A$ niger, and a further 10 workers had clinical evidence of occupational asthma without sensitisation to $A$ niger. It was suggested that much of the sensitisation had occurred as a consequence of exposure to aerolised free antigen given off by the washing process (wherein impure calcium citrate solution was washed by water that contained remnants of soluble $A$ niger antigen), rather than by exposure to free spores.

After that investigation, measures were taken to reduce the exposure of workers to aerosolised antigen. The washing and filtering process was enclosed and exhaust ventilation applied. Respirators were provided for use when access to the area was necessary. Workers and managers were educated about control of risk. Also, to monitor the efficacy of these measures, the workforce was invited to participate in a two-yearly survey of respiratory symptoms, smoking habits, and peak flow rate, together with skin testing for common allergens. Over the period of the study, from 1983 to 1991 , a large number of the original workforce left the industry, although there was also some recruitment. Recently there has been substantial reinvestment and a completely new plant, almost wholly enclosed, has now been commissioned.

The objectives of the study were to record the effect of control measures in preventing sensitisation and work related symptoms in the workforce, including established and new employees, and to monitor the effect of these measures on workers already sensitised.

\section{Methods}

POPULATION

At the time of the first survey, in 1984, 278 of the original 343 workers remained in the factory. All were invited to participate, from the managing director down, including both industrial and office workers. Only 12 did not, a $96 \%$ response, and complete data were obtained on 261.

Full surveys were repeated about every two years. We report here the results from the three completed in 1984, 1988, and 1991. In the 1988 survey 61 of the original workers had left but 76 extra workers had been employed. One other had arrived for the 1991 survey. Some very short term workers and external contractors did not take part in the surveys. By the 1991 survey, 101 of the original 261 workers and 37 of the later recruits remained, 160 and 39 respectively having retired or been made redundant (figs 1 and 2).

\section{QUESTIONNAIRES}

Specially designed detailed questionnaires of respiratory symptoms, including when rele-

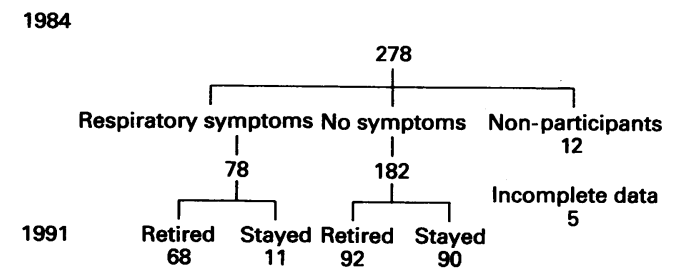

Figure 1 Outcome of the original workforce. 


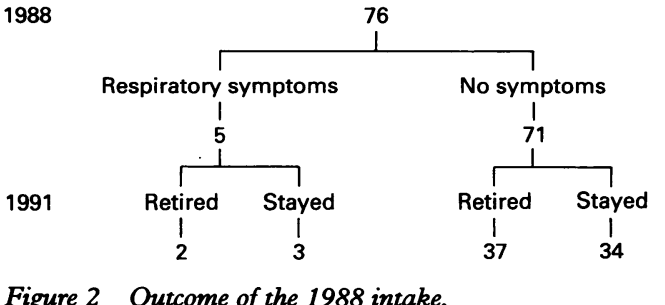

Figure 2 Outcome of the 1988 intake.

vant whether symptoms related to work, were given by a trained nurse (DW) to all current and new employees. The questionnaire was derived from that used by one of us in surveys of wool workers. ${ }^{2}$ A short modified questionnaire was used for follow up surveys. This recorded the presence of symptoms and the worker's subjective view as to whether these were more or less severe than on the previous survey. When the answers to the questionnaire suggested that symptoms were related to work detailed clinical investigation including serial peak flow recording was carried out.

\section{SKIN TESTS AND LUNG FUNCTION}

Prick skin tests were given by DW and results recorded as positive for wheals greater than 2 $\mathrm{mm}$. No wheals were found in response to control solutions in this survey. Commercial antigen to grass pollen, Dermatophagoides pteronyssinus and $A$ niger, together with negative control, were used.

WORKPLACE MONITORING

For practical and financial reasons, monitoring of soluble antigen in the air was not possible. Instead, we carried out regular air counts of spores of $A$ niger in the workplace. Samples were taken by Anderson sampler at weekly intervals on to selective media, and colonies were counted.

\section{Results}

WORK RELATED SYMPTOMS

Of the 261 people surveyed in 1984, 10 subjects were considered from their answers and from clinical follow up to have had work related asthmatic symptoms. Seven of these had negative skin tests to $A$ niger. Three had left by 1988 and all 10 by 1991 . One reported his symptoms to have lessened by 1988 , but the others reported no change. Workers who did not report work related symptoms in 1984 did not develop them subsequently.

Of the 76 new employees in the 1988 survey, none reported work related symptoms, and none of those 37 who remained at the 1991 survey had developed such symptoms.

\section{COUGH, WHEEZE, AND BREATHLESSNESS}

One or more of these symptoms were reported by $79(30 \%)$ of the original 1984 survey population. Of these, 29 had positive skin tests (15 to $A$ niger alone or in combination with others). Sixty eight of the 79 with symptoms had retired or been made redundant by the time of the 1991 survey. Of the
76 new employees, only five recorded respiratory symptoms. Three of these five, together with 34 others of the 76 remained to participate in the 1991 survey.

Of the 138 taking part in the 1991 survey, 10 of the 14 who had previously reported cough or wheeze recorded an improvement whereas four reported worsening. One subject recorded symptoms for the first time, in 1991. In none of these were the symptoms shown to be work related by clinical investigation.

\section{SKIN TESTS}

Of the original 261 people in the survey population, $63(24 \%)$ had one or more positive skin tests, of whom 25 were positive to $A$ niger alone or in combination. Twenty nine of the 63 had respiratory symptoms, including 15 of those allergic to $A$ niger. Twenty five of these 29 retired or were made redundant before 1991 .

Of the 76 new employees, 12 had positive skin tests (four to $A$ niger) initially. Five of the 12 had respiratory symptoms, but only two of these had retired by 1991 . Three of the four who were positive to $A$ niger remained at work in 1991 .

\section{CHANGES IN SKIN TESTS}

Of the 172 in the total survey workforce of 261 original and 76 new employees who had had two or more skin tests, all but seven showed the same result each time. Of these seven, three (two $A$ niger and grass, one house dust) became negative, two others lost sensitivity to $A$ niger, retaining others, and two lost other sensitivities but retained that to $A$ niger.

\section{MONITORING OF A NIGER}

The mean concentrations of airbone $A$ niger in the main part of the factory, measured in two places, were $4.9(0.68) \times 10^{2}$ colony forming units $/ \mathrm{m}^{3}$. These figures compare with an average of $<5 / \mathrm{m}^{3}$ in the normal outside air.

\section{Discussion}

There is little information available to guide those who would wish to reduce the risks of asthma in the workplace. When we were confronted with the problem in this citric acid factory, we took the pragmatic approach of improving industrial hygiene and monitoring the effects of this on both workers and the environment of the workplace. The results have been reassuring.

Aspergillus niger is well known as the black mould that grows in damp places. The best known member of the family, $A$ fumigatus, has been incriminated as a cause of asthma, allergic alveolitis, bronchopulmonary aspergillosis, aspergilloma, and localised and diffuse aspergillosis, especially in the immunosuppressed. ${ }^{3}$ Its pathogenetic mechanisms have been extensively investigated. ${ }^{4}$ There is no reason to suppose that other Aspergillaceae have different pathogenic potential, and asthma and allergic alveolitis have been described after exposure to several 
others. ${ }^{5-7}$ The importance of $A$ fumigatus as a pathogen probably relates to the fact that it is the species that is most prevalent in the air. especially in the winter when spore counts may reach $60 / \mathrm{m}^{3}$ in urban air. ${ }^{89}$ Much higher concentrations may be found around locations such as compost heaps. By contrast, $A$ niger is rarely recorded in concentrations as high as $5 / \mathrm{m}^{3}$ in urban air, ${ }^{8}$ and is only likely to be a problem indoors when colonising buildings or when used as part of an industrial process.

When we were confronted with the problem of occupational asthma in this factory we faced a familiar dilemma in balancing the risks to health against the costs of preventive measures. The main sources of airborne antigen were identified and steps were taken to enclose these parts of the process and to apply exhaust ventilation. Of necessity, these steps were only partly effective, and respirators were provided for men who had to work in areas where antigen concentrations could be high. For these reasons, it was considered necessary to carry out intermittent medical surveillance of the workforce.

The most striking finding was the discrepancy between retiral from the workforce in those who were fully fit and those who had reported symptoms to the survey; most of those who had symptoms, work related or not, retired. All those in the original survey with work related symptoms had retired by 1991 , clearly a healthy worker selection in a workforce in times of financial difficulty. There was no deliberate policy to retire the less healthy over this period.

Sixty one of the original workforce had retired by 1988 and a further 99 by 1991 . In only four of those 99 had new symptoms of asthma developed and in none was it found on investigation to be work related. Furthermore, none of the original workforce or the 1988 recruits who survived to the 1991 survey had developed either occupational asthma or even skin sensitisation to $A$ niger. We thus believe that the very simple measures that we took were effective.

These results provide evidence that $A$ niger is a relatively weak antigen. The concentrations of spores recorded in the factory have been consistently about 100 times those encountered in the outside air, and equivalent to concentrations of $A$ fumigatus found in Britain in the winter. In our earlier paper, $5 \%$ of the workforce showed skin sensitivity to $A$ niger, whereas by the final 1991 survey no new sensitisations had occurred and three had lost their skin sensitivity to $A$ niger. It is likely that despite our measures these workers continued to be exposed to airborne soluble antigen as well as spores.

It should be noted, finally, that although skin tests were carried out on all new employees, this was only used as a means of guiding deployment and advising on preventive measures, and workers were not excluded on the basis of positive tests. None of the recruits with positive tests, even when positive to $A$ niger, developed work related symptoms.

We conclude that a pragmatic approach to control of exposure to asthma causing agents, based on an assessment on the likely antigenicity of the agent is reasonable in industry. Where, as in the case of our factory, a period of complete lack of control has resulted in only a low prevalence of asthma and sensitisation, simple hygiene measures are likely to provide reasonable protection to the workforce. Worker surveillance plays an important part in ensuring the effectiveness of such measures and in investigating any possible failures.

We are grateful to $\mathrm{Mr}$ Tony Tolhurst for the fungal spore counts, to Mrs Lesley Alexander for secretarial help, and to the factory management and workforce for their assistance and co-operation.

1 Topping MD, Scarisbrick DA, Luczynska CM, et al. Clinical and immunological reactions to Aspergillus niger among workers in a biotechnology plant. $\mathrm{Br} \mathcal{F}$ Ind Med 1984;42:312-8.

2 Love RG, Smith TA, Gurr D, et al. Respiratory and allergic symptoms in wool textile workers. $\mathrm{Br} \mathcal{F}$ Ind $\mathrm{Med}$ 1988;45:727-41.

3 Seaton A, Seaton D, Leitch AG. Crofton and Douglas's Respiratory diseases. Edinburgh: Blackwell,

4 Seaton A, Robertson MD. Aspergillus, asthma and amoebae. Lancet 1989;2:893-4.

5 Metzger JB, Garagusi VF, Kerwin DM. Pulmonary oxalosis caused by Aspergillus niger. Am Rev Respir Dis 1984;129:501-2.

6 Laham MN, Carpenter JL. Aspergillus terreus, a pathogen capable of causing infective endocarditis, pulmonary mycetoma, and allergic bronchopulmonary aspergillosis. Am Rev Respir Dis 1982;125:769-72.

7 Riddell HVF, Channell S, Blyth W, et al. Allergic alveolitis in a malt worker. Thorax 1968;23:271-80.

8 Mullins J, Harvey R, Seaton A. Sources and incidence of Aspergillus fumigatus. Clin Allergy 1976;6:209-17.

9 Mullins J, Seaton A. Fungal spores in lung and sputum. Clin Allergy 1978;8:525-33. 